dairy organization in the world. Although there are 290 million cattle in India, the provision of fresh meat for the troops is made more than usually difficult by the climate, the enormous distances involved, the many infectious diseases and the fact that Indian animals are not bred and fattened for slaughter. Several hundred thousand animals are bought each year for slaughter, and the Army Veterinary Service examines and selects them and cares for their health. Many animals must spend from three to ten days in the train before they reach their destinations. Slaughter stock are transported by sea voyages which may last from one to five days, by train, by motor, on foot or by a combination of all four methods; and the hot weather, traffic congestion, compulsory use of all-metal wagons and other factors increase the difficultios of organizing such journeys. Animals are never kept in the train for longer than forty-eight hours; but the rests between spells of travelling expose them to the many infectious diseases of the Far East.

A further responsibility of the Army Veterinary Service is the breeding, through local development schemes, of pigs, rabbits and poultry, and these animals present their own disease problems. The Army Veterinary Service also inspects the meat and provides the Veterinary Wing of the Chemical Defence Research Establishment, which deals with the defence of animals against gas warfare. The Army Veterinary Laboratory Services and their mobile laboratories prepare vaccines and undertake routine and other diagnostic work. Nowhere else in the world, says Brigadier Peatt, does the veterinary officer encounter such a variety of diseases. A good example of the military importance of these diseases is the outbreak of the equine trypanosomiasis called 'surra' in 1942 on the Assam-Burma border. At one time 17 per cent of the horses and mules were put out of action by this disease, but the control measures adopted reduced the percentage of infected animals from 17 per cent in 1942 to 7 per cent in 1943 and 2 per cent in 1944. The Army Veterinary Service devised the method of injecting 'Antrypol' intravenously and obtained by this method 90 per cent of recoveries from this disease. Anti-surra units have now been formed.

Two other important diseases are anthrax and rinderpest, against both of which all cattle purchased and many sheep and goats are immunized. Rinderpest is the most important cattle disease in India. Although many thousands of cattle owned by civilians have died near the military dairy farms, the losses on these farms have been negligible (less than 1 per cent in 1943-44). Outbreaks of glanders have been quickly controlled, epizootic lymphengitis and strangles are being studied, precautions against foot-and-mouth disease, which is extremely widespread in India, are being taken, and the control of variola, which is usually introduced to dairy farms by buffaloes which have been bought, is being improved. Among the serious diseases of the smaller animals are pasteurellosis, salmonellosis and Ranikhet (Newcastle or Doyle's disease), and research upon the control of these is being done.

It is clear that the Army Veterinary Service is doing in the Far East a fine job which is vital to the success of the war against Japan. The quiet efficiency and progressive spirit of this work show how much the veterinary profession can contribute to the solution of the vast food problems of the post-war world.

\section{ARTS AND CRAFTS OF THE COOK ISLANDS}

$T N$ a large and profusely illustrated volume the 1 Director of the Bishop Museum gives a comprehensive and detailed account of the material culture of the Cook Islands*. The Polynesians are known for their clever workmanship and, as the illustrations show, these islanders are no exception, whether they are carving wood or plaiting fibres. The greater portion of the book is concerned with a description of the arts and crafts, including religious symbols, and this is followed by a discussion of their implications.

A study of the material culture of the Cook Islands shows that there are three cultural periods, a fact that may be best understood by the racial history of its inhabitants. The Polynesian ancestors, as it is now recognized, came from the mainland of Asia into Indonesia where they adjusted their continental culture to suit volcanic islands the fertile soil of which produced abundant food and where a rich culture developed. From Indonesia they passed on to Micronesia, the coral atolls of which formed a barren contrast; arts and crafts suffered drastic changes owing to the loss of food plants and raw material of wood and stone, and the people retrogressed from the stone age to a shell age. From here these ancestors, in the course of ages, moved westwards and finally arrived at the Society Islands, where they were once more on volcanic soil, so that stone was again available and the rich soil provided ample food. On these islands the Polynesians settled and from them they radiated out to the various island groups they were destined to colonize. They rediscovered the use of stone, and food plants and animals were probably introduced from the Melanesians in Fiji.

It was in this period of expansion that the Cook Islands were settled-roughly six hundred years ago - the culture being identical with that of the parent colony of the Society Islands, and this forms the first phase. Modifications and local developments have naturally taken place in both island groups so that it is difficult to give an exact picture of this early stage, but certain elements can be reconstructed. Some cultural processes, which may be regarded as stable, persisted unchanged until European occupation; examples of these are the plough method of firemaking and the earth-oven. The second period was one of developments rather than of any very sudden change. These may be due to diffusion owing to migration or importation or they may be caused by the substitution of another material or technique. Occasionally a new local technique is invented, such as the decorated borders to the pandanus sleeping mats that are peculiar to the Cook Islands.

The third period begins with the arrival of the white people. Early European voyagers bartered hoop iron and axes for fresh food, and the natives were quick to realize the superiority of metal over stone and to acquire it whenever possible. With the coming of the missionaries clothing was altered both in design and in material, and as timge went on most of the old culture became obsolete. The new generation has grown up under these changed conditions and the cultural invasion is firmly established, for the natives will not give up the material comforts of to-day for any mental satisfaction connected with a sentimental past. K. RISHBETH.

- Arts and Crafts of the Cook Islands. By Te Rangl Hiroa (Peter H. Buck), Bernice P. Bishop Museum Bull. 179 (1944), 